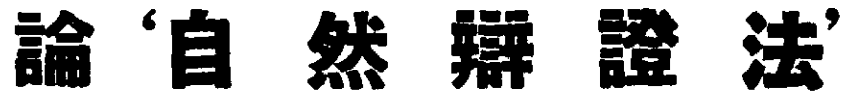

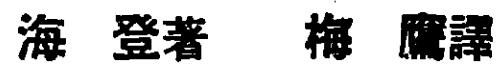

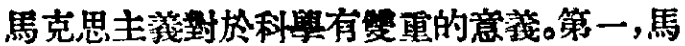
克思主澺者是把科學和人類其他的活動結合着一 起研究们。他們指出:任何社會的科祭活動是怎案

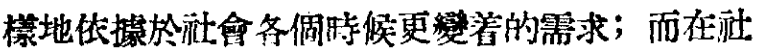
會的生座方法過程中，科學又怎樣改變了硅會的 生產加法; 而因此改變了整個注會。这一種分析對 於任何科學性的愿研究是必須的; 即使是非馬 克思主㼁者, 現在也已部分的接受這一事惯, 但 是，第二，馬克思和恩格斯不僅僅以社會變化的分

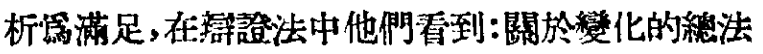
則的科罢，並不沶存在於访會和人類的思維中,而 且還存在於第人類思維所反映山來的外界環境當

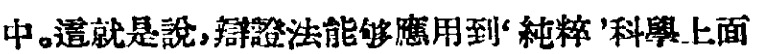
去，正如它能分析科學對社會的關係一樣。

科學家已經逐潮熟悉了把馬克思主義的觀 念, 應用到科舆與㹨會的筑係上。有的全部或部份

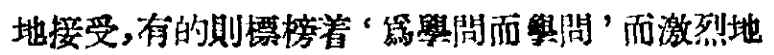
反對。然而許多人並不知道馬克思主茷在科學與

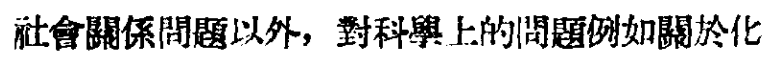

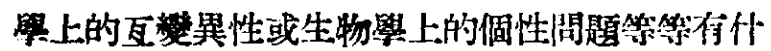

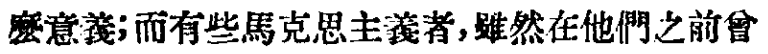

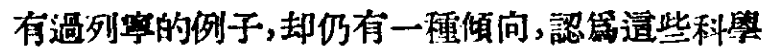
與折罢的問題的研究並不重要。1908年, 俄國革. 命失敗，革命運動必需重新建立，在那時候列察 看到祇有在健全的理論基磷上，革命工作才能够 晸好。因此他寫下了'唯物論與經驗批制論'。在這

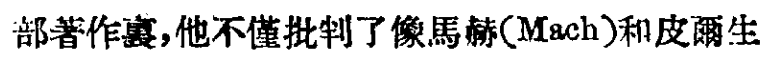
(Pearson)等哲學家，還批制了海落(Herty)，湯姆 生(Y. Y. Thomson) 和柏克勒爾 (Becquerel) 等: 物理學家，造些人的墢見，是可以用唯物的，也仃

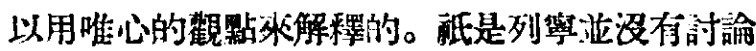
全部利蜠的企圖。他所論及的主要的是當時正在
展開的物理舆上的革命，而對於天文舉、地質罢、 化擧或生物學都很少提到。

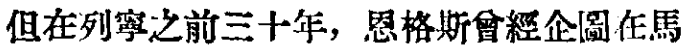
克思主㬢讪让場上來討諭全部科學。他始終是科 舉的㠘澘者，從1861年起，恩格斯在曼徽斯特與 化學家叔萊茉 (Schorlemmer) 常在一起,許多年 來他和叔萊荣以及馬克思滆渝着科學上的問題。

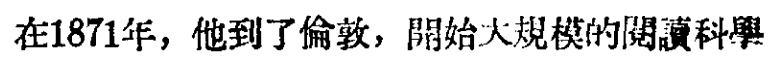

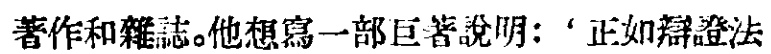
之適用於㹻史中的偶然事件一樣, 在自然界㶵數

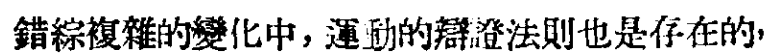

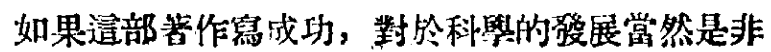
常重要的。

可是,在恩格斯面前除了政治工作以外,還有 其他理論方面的工作努做，例如恃林必須答焉，创 括全部人類知識的“反杜林論 '如果完成了, 那它

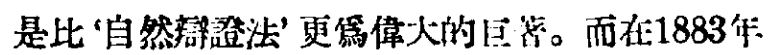
馬克思逝世以挠，他有着更巨大的把 “資本渝” 的 竄完成的工作。而且除此以外他竄下了“紧闑巴

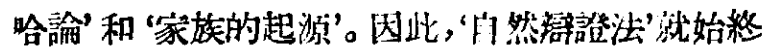

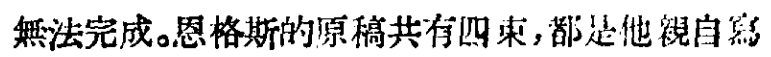
的, 包括窟馬克思保留着的許多引自希腹折學家

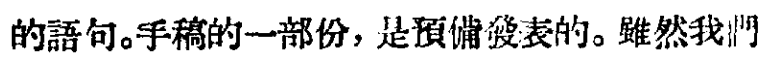
看得出來他是一定會加以修正的。手稿的大部份 融是恩格斯希壁以後再把它完成的筆記, 很難

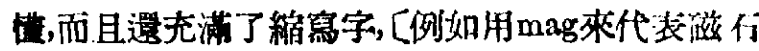

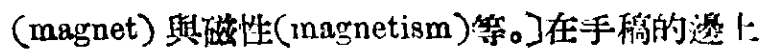
空白的地方還偶而有着染竄與第略的字吤。活後, 踓然手稿大部分是用德文寫的, 但恩格斯也问樣 用英文和法文來思慗，因此偶而就有了们把夾雜 德文、英文、法文的語句。翻譯工作也就變得非労 闲難, 面问不同部仿的次序也不容易確定。 
手穆的大部分似乎是1872而1882年中間察成 的, 這就是說它討諭到分十年以前的科學。因此 要是不明瞭賞時科學理諭和顀践情况的各種史察 那是很難順利地讀得一去的, 侧如現在所說的能

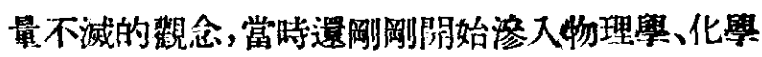
和生物翼部門去。而且在理解和礁用方面還都很 不完全, 所用的 'カ', 運動'以及 '活力'(vis viva) 譄些宇腿，在現在看起來都應當用 ‘能”狺個字 來代替。而如 “運動的基本形態”，“连動的度量一 功', '䇣' 等邆些論文, 主要都是諭述當時由於能 的不完全或者錯誤的理論而引起的爭諭的。這些 論文它們很有興趣地說明了造些問題的觀念如何 逐渐地璠展, 而當時恩格斯又如何解决那些論争。 踓然現在那些諭拿大部分已經解决了。‘活力’也不 再和“動能”這名詞重覆的使用了, “力’這個字在物 理學上也已有了碓定的意義。而師使祇是因息恩 格斯在以後“潮汐摩擦' 的論文中用了比較近代的

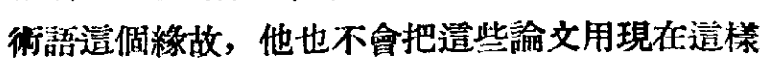
的形式墢表的。我們對於這些論文的興趣,並不在 理諭方面的詳細批制（因第許多理論已經失了重 要性), 而是在於恩格斯怎樣與理渝上的問題作鬥 争。造在討論電的論文中表現得更窟明顯。對於惠 特曼的矛盾的批評，那是很有趣的。對於電的作用 和化學作用兩者之間的關係作了更深入的研究。 恩格斯得出結論馀, “尷會使得兩方面的研究都得

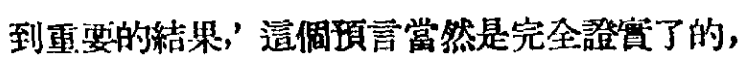

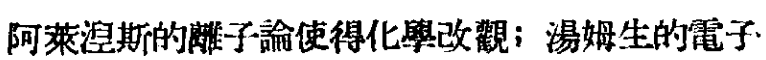
諭使行物理學起了革命。還有, 濖份手稿一定是

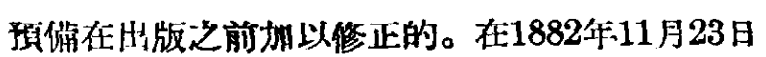
恩格斯䳆給馬克思的一封信中就指出西門在就任 '英國協會' 主席時的演說裹, 定出了一個電力的 新單位一瓦 (Watt), 說瓦與阻力和電流平方 的乘積成比例, 而電動力則與阻力和電流的乘瞔 成比例。在討諭 “運動的度量一能”這一篇諭文 中, 恩格斯用邆兩個定義來和動量及能的意義相 比较, 指妆如果不涉及能從一個形计轉換到另一 個形式的時候,那罂能量與速度之間，電動力與電 流之間，造兩種情形都是一個簡單的比例。但當能

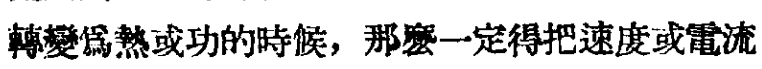
的数字平方, 才可以得出正確的數值。所以恩格斯 說: “因此，逪是一個運動的總法則，是我第一個提 出來的。” 現在, 我們掌然能够領會第什㦄是如此
的, 因䈍動量與電動力都是向量，賞速率與電流的 方向是反的時候, 動量與電動力也就反過來。但是 能亚浔有改變。因此在公式實速率或電流必須本 方 (或是其他的脽次方); 因篇任何負數的平方也 是正數, 和同一正數的平方值是相等的。

在討論“潮汐摩擦”的論文中，恩格斯犯了一

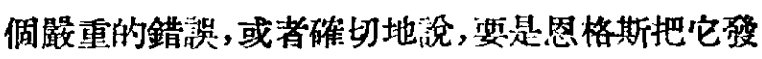

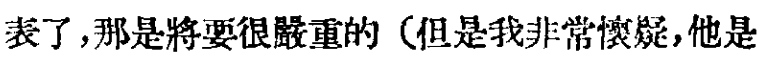
否會把它發表)。那是在' 反杜林諭'手稿當中的註 解寒(第314頁)，他支寺了一個在十九世紀普遍流 行的觀點.說我們之所以能够找到不待論說, 自然 明白，像數學公理那㧼的员理，是因瓷我們的祖先 已經碓信了它們的真赛性，而對於布西門族(南非 州以游牧篇生的種族)或澳洲黑人，那就不會哭需 諭述而自然明白的。現在看來，這倜観點無疑是不

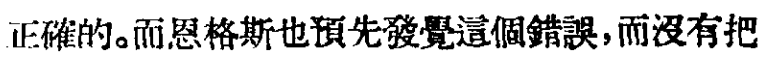

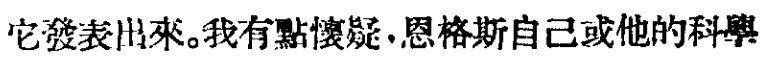
界朋友像叔莱菜會在“潮汋摩擦”的諭文中察學譄

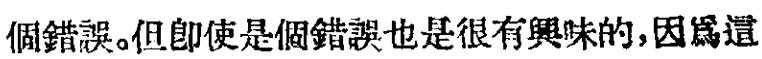
樣一㑉錯誤，經過了不正確的推諭，却引运了“師 使汥住海洋,白天也會縮短的 那窥一個正確的結 諭。這類錯莈在科舉史上是非常多的。

書中别的地方例如在討 諭 星 及原生動物方 面,還有着顯然是不正確的叙迅。但是㯰不能责備

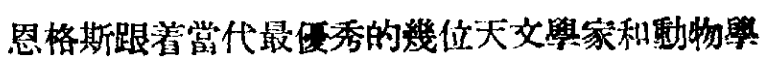

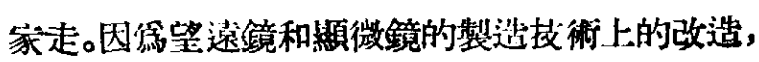
六十年以本我們的知諳當然是增加得很多的。

在另一方面，恩格斯對於徽分舉的評沋，踓然 不能㷳用到今天所溝授的造門數學方面去, 但在 他那個時代和以後一段時期內都是正確的。他指 出徽分學確是由於矛盾而砤展起來的。今天，對於 他所論及的許多定理已經有了誁多有力的嘴明。 而有些數學家宣稱已把矛盾洞隇了。而䍃祭上是 他們僅是把矛盾遮掩起來, 而自己則留在数䍘遗 輯的範瞦裹。不但他們用一切力量從一一套公理演 繹蛙所有的整學和應用的法則是失敗了, 而且郭 特爾(Godel)也已經澄明了他們必定要失敗的。因 此在事惯上，微積分雖然可以不包括恩格斯所諭

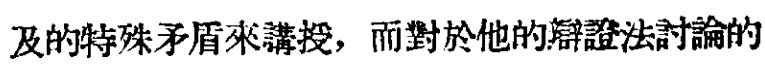
正確性,則是不能駁倒的。

我們在這些批評以後，再看看恩格斯對於他

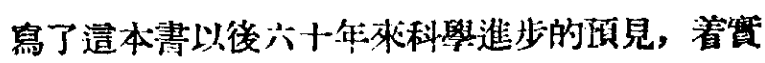




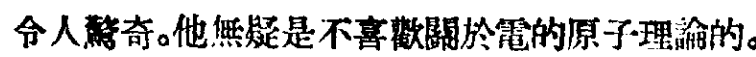
而道個理諭在1900年至1930年間都佔着優攀, 直

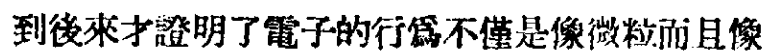
波動系統, 而在道以前他很可能被人認第是 “資 錯了賽馬票'。他堅稱生命是蛋白筫活動狀况的特 有形式, 對於大多数的生物化學家說起來造種㴏 法是太片面, 因第每一個細胞含有蛋白質以外的 伡多複雜的有機物。记在最近汇年, 才澄阴了热 数種純粹的蛋白質䫏示着生物䯏一種最重要的特 徽,它門在不同的環境之中自己繁殖着。

舅晳了運用恩格斯的思維方法, 我們到處都 能得到谷處，但是我想書中論及生物眎的部份，對

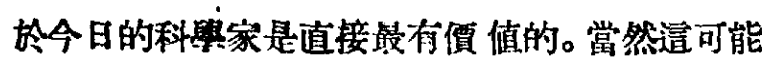
是由於我是個生物學者，我能矽在這部分學察到 恩格斯思想的微妙。而在論及物理學的部分中却 錯過了:也䚺是由於在最近六十年來.生物藇汥有

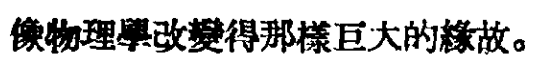

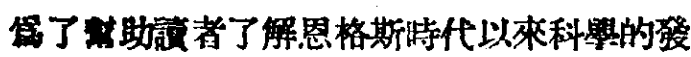
展,我在文中加了許多註侽。恩格斯有些時候是錯 塥了，少數颜者或許會反對我把它指出來，但恩格 斯是不會反對的。他完全明白他蕜非全無錯言的, 而在工人運動中並無主教或活的偶像。在' 1844年. 英國工人階級的情况' 英譯本裹（1885年美國仙 版. 1892年英國比版)，恩格斯在四十八年以後所 作的序言中說: ‘我曾竭力當心不要朋去畫中許多

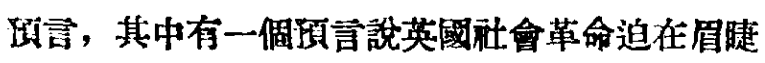

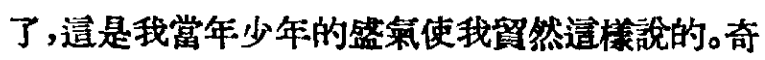
怪的是，並非那些頋言大多是錯誤的，倒是有許多 已經證售是正確的。”

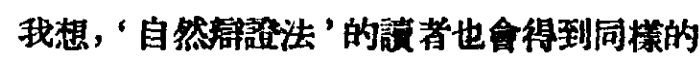
結論。

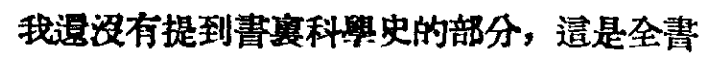

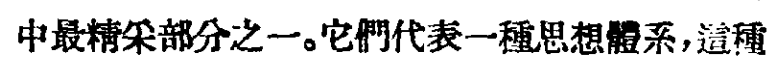
思想能系在馬克思和恩格斯其他著作㗬中一通運 用着。而且以後别的人還把它弦展了，因此許多禛

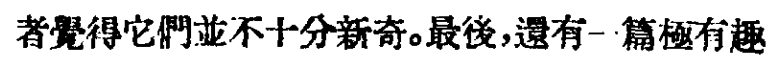
的論文: “精神世界的科學研究”。在唯物論者中間, 份一種忽略运類問題的侻向。而值得注意的是恩 格斯立不這樣做，相反的，他提出了許多在他那時 㑨認绿是玄妙和神秘的現象, 而得到和多数科學 研势者在邆方面听得的相同的結論，只是那些人 不像恩格斯,在他們的著作赛，缺之一般的常識和
幽鼠。

1895年恩格斯去世的時侯, 遝份手稿到了本 斯坦因 (Bernstein) 的手中而浔有把它以版。造 不僅對於馬克思主義, 而且對於所有自然科學备 部鬥都是一称权大的不幸。1924年，本斯坦因把 這份手稿（或者林是其中的一部份）給受因斯

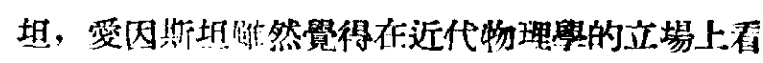

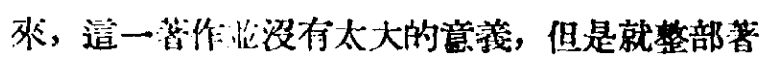

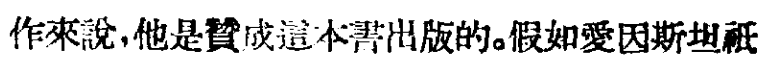

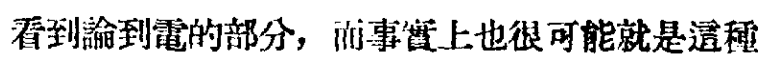

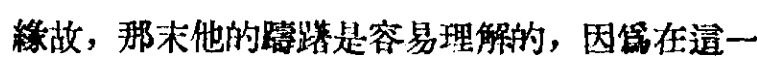
部所討論的問题，在現在看起來都已緛不值得再 來提起。邆份手稿首先是由列然諾夫 (Riazanov) 編輯，在1927年印行。然而1935年阿道拉柋斯基 (Adoratski) 的版本则更好, 前一版本中有些意

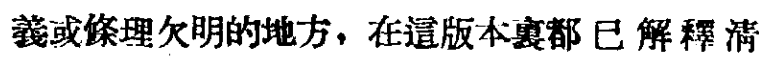
楚。

如果對恩格斯的思維方法較第㛙悉的活, 那

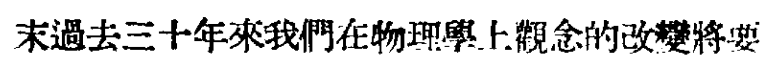

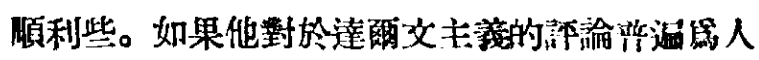
知道的話, 那末我也諸是省却許多混璠思索的人 當中的一個。因此我全心全意地排迎“自然群澄法” 英譯本的出版，蓝希窐以後的科藇家能够㺕學它 可以使他們的思想更富有彈性。但是决不能以僬

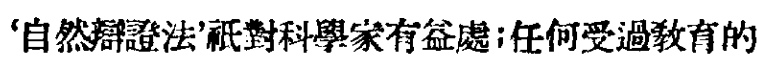
人,以及最主错的是任何研究哲舆的人，會墢現造 本書對他或她有更多的好虔。特別是第一、二、七、 九、等五音。

恩格斯之所以成第這棦偉大的作家, 其理由 之一就是他大概是虽時頂河凳的人。他不僅在經 湾學和史學方面有濎博的知識, 而且他有足够的 學識討諭程馬婚姻法中一句意嘎糊模的拉丁文短

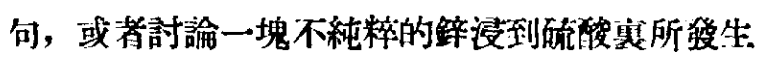

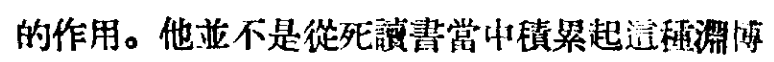
的知識來的, 而是在政治活動之中担任重管工作 的時侯, 在經營事業的時候, 摆至於在䰺狐的時㑨 累積起來的。

他需要這種知識, 是因第他和馬克思發現棓

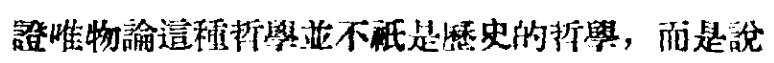

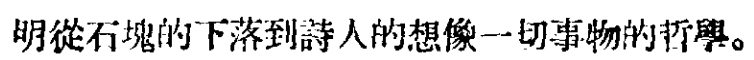
面它特别注重所有過程的內不断距, 以及不社是

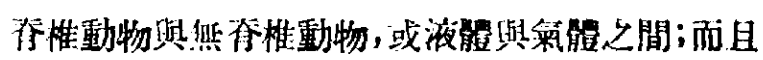




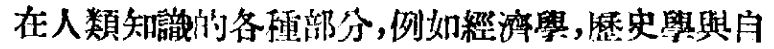
然科學之間人們所劃分的完全是人媱的差则。

第二率包括了這種哲學與自然科學關係的大 粡。這在“聯共(布)黨史'第七竟中,佮一段非常審 㣀精煉的提要, 但研究這問題的主要資料,則是恩 格斯的“貨爾巴哈論”和“反杜林諭”,列拿的“唯物 論與經驗批判論 '以及、馬克思的許多作品。正因第 它是一種活的折學, 亚且有無数的具體應用, 因此 當把它運用到婑史、科學或者任何其他最有舆趣 的部門中, 它的全部力量和它的重要性, 祀能逐濑 地能驗。由於這佪原因, 一位主要的興趣在政治或 䍃沾方面的讀者, 當他研究了恩格斯怎樣以讋證
法運用於自然界以媵，就會回到他的主要興诹所 在方向成给一個更好的教證唯物諭者, 而因此也 僦會成焦一個目光清楚的政治家或經湾家。

現在，假如我們要瞙解這倜我們人類所處的， 特別是我們自己國家所處的極端複雜的環境, 並 且瓷了要看出一更好世界的前涂，那末清哳的思 想是非常需要的。對恩格斯的學習，會警我我們去 反對那種在今日流行的, 胡說八道的解决辦法, 更 會垶助我們在我們自己的時代的巨大事件當中担 負起智慧的和勇敢的工作。

〔原文係海登 (J.B.S. Baldane) 第英譯本 '自然誩證法' 所作的的序言一一譯者]

\section{電氣在蘇聯農業中的若干應用 電燈代替太陽}

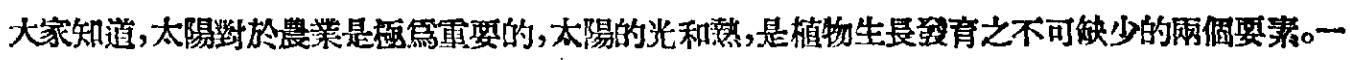

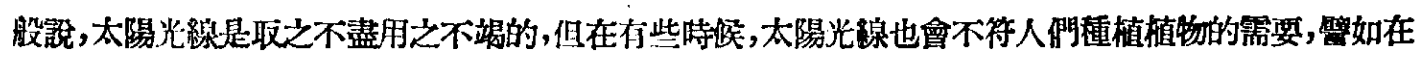

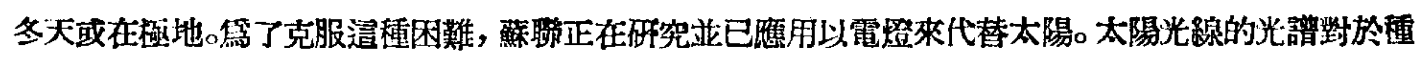

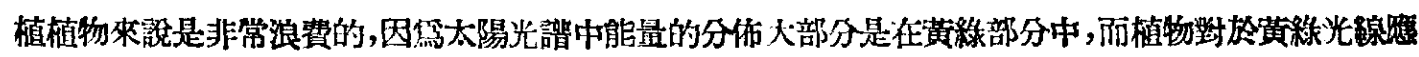

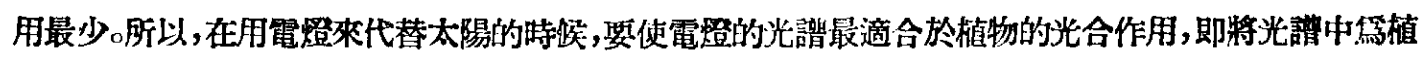

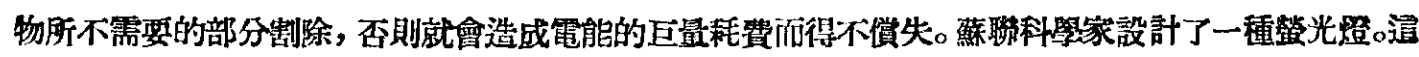

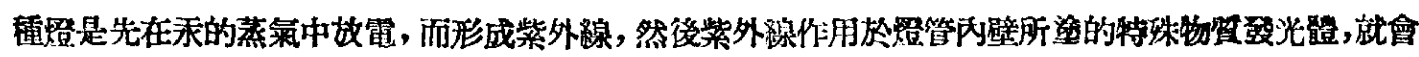

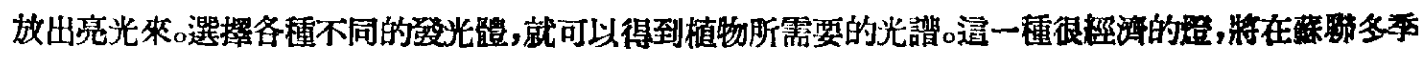

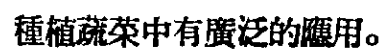

\section{電與美彩}

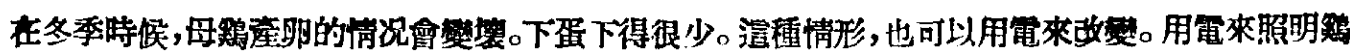

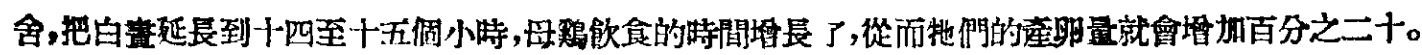

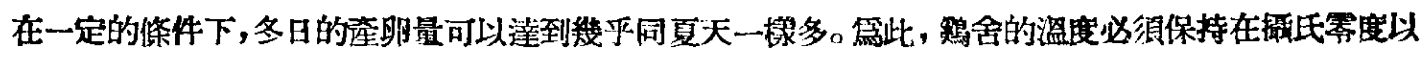

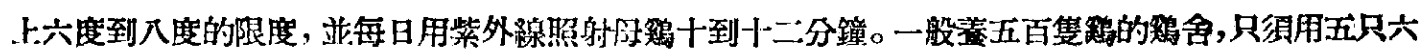

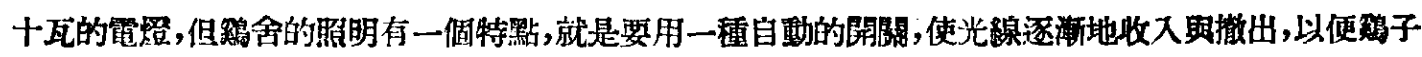
的耧息。

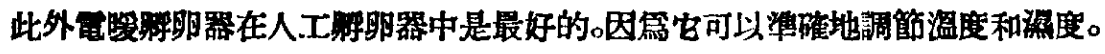

\section{電カ殺蟲}

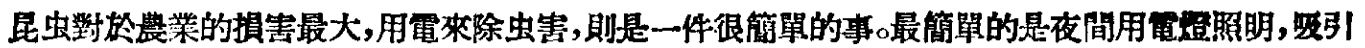

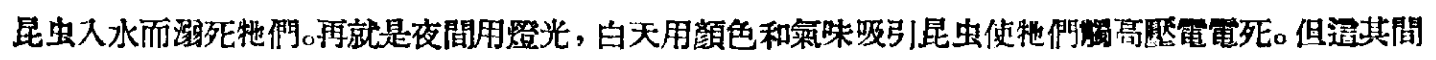

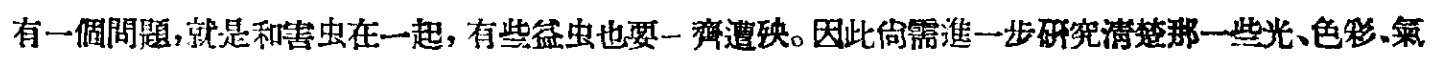
味只會吸引䜤虫而不會吸引盍虫, 然後再加以利用。

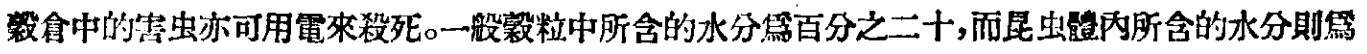

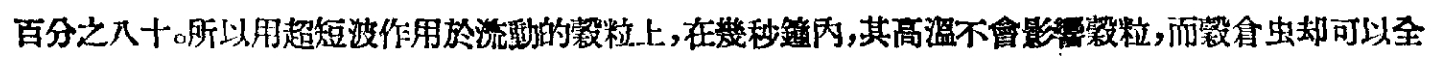
被烧㱜。同特僖粒在造時得到了就燥,亦更便於睁藏。

(中筑友好 2 管 7 期) 